\title{
Gambling Motives: Do They Explain Cognitive Distortions in Male Poker Gamblers?
}

\author{
Sasha Mathieu ${ }^{1}$ Servane Barrault ${ }^{2,4} \cdot$ Paul Brunault $^{2,3}$. \\ Isabelle Varescon ${ }^{1}$
}

Published online: 17 June 2017

(C) The Author(s) 2017. This article is an open access publication

\begin{abstract}
Gambling behavior is partly the result of varied motivations leading individuals to participate in gambling activities. Specific motivational profiles are found in gamblers, and gambling motives are closely linked to the development of cognitive distortions. This cross-sectional study aimed to predict cognitive distortions from gambling motives in poker players. The population was recruited in online gambling forums. Participants reported gambling at least once a week. Data included sociodemographic characteristics, the South Oaks Gambling Screen, the Gambling Motives Questionnaire-Financial and the Gambling-Related Cognition Scale. This study was conducted on 259 male poker gamblers (aged 18-69 years, 14.3\% probable pathological gamblers). Univariate analyses showed that cognitive distortions were independently predicted by overall gambling motives $(34.8 \%)$ and problem gambling $(22.4 \%)(p<.05)$. The multivariate model, including these two variables, explained $39.7 \%$ of cognitive distortions $(p<.05)$. The results associated with the literature data highlight that cognitive distortions are a good discriminating factor of gambling problems, showing a close inter-relationship between gambling motives, cognitive distortions and the severity of gambling. These data are consistent with the following theoretical process model: gambling motives lead individuals to practice and repeat the gambling experience, which may lead them to develop cognitive distortions, which in turn favor problem gambling. This study opens up new research perspectives to understand better the mechanisms underlying gambling practice and has clinical
\end{abstract}

Sasha Mathieu

sasha.mathieu@etu.parisdescartes.fr

1 Laboratory of Psychopathology and Health Processes EA 4057, University Paris Descartes, Sorbonne Paris Cité, 71 Avenue Édouard Vaillant, 92100 Boulogne-Billancourt, France

2 Laboratory of Ages of Life Psychology and Adaptation EA 2114, Psychology Department, University François Rabelais de Tours, 3 Rue des Tanneurs, 37041 Tours, France

3 Equipe de Liaison et de Soins en Psychiatrie, Psychiatry Department, CHRU de Tours, 2 Boulevard Tonnellé, 37044 Tours, France

4 Centre de Soins d'Accompagnement et de Prévention en Addictologie (CSAPA 37), CHRU de Tours, 37044 Tours Cedex, France 
implications in terms of prevention and treatment. For example, a coupled motivational and cognitive intervention focused on gambling motives/cognitive distortions could be beneficial for individuals with gambling problems.

Keywords Gambling · Gambling motives · Cognitive distortions · Problem gambling $\cdot$ Poker

\section{Introduction}

Gambling is characterized as an activity whose outcome is based mainly or totally on chance, which involves an irreversible provision of money or an object of value beforehand. Different gambling types include games of luck (lottery, slot machines, scratch-cards and roulette) and games of skill (poker, blackjack, sports and horse betting). The outcome of games of luck is due only to chance, while games of skill depend on luck, strategy, experience and knowledge parameters. To date, few epidemiological data are available on European populations, which can be explained by the lack of research on the prevalence of gamblers in the general population. Different sets of practices can be identified depending on the intensity of gambling, defined by its frequency or the amount spent on games. In France and Northern Europe, 1-2\% of problem or pathological gambling occurs in the general population. A similar prevalence was found in Canada and New Zealand (Costes et al. 2011). However, these estimations are much lower than those found in the United States and Australia (around 5\%). Differences in terms of prevalence between countries are still widely discussed. Accessibility to gambling and the materials used to obtain these data are some explanations regularly put forward.

Among types of gambling, poker playing appears to have special features, particularly the involvement of both chance and strategy in the game's outcome (Barrault et al. 2014), which could influence players' perception of chance in the game (Barrault and Varescon 2013). Furthermore, poker players show specific gambling problems (Bjerg 2010; Barrault et al. 2014). Evidence from the literature thus suggests that excessive poker players may have a specific psychological profile.

While the practice of gambling can be seen as a personal choice, it can be influenced by factors favoring it or not (Burlacu et al. 2013). Cognitive distortions are one of the variables that influence involvement in gambling activity. Inherent to gambling situations, all gamblers, including non-problem gamblers and gamblers who have good numerical and objective probabilities of winning, are susceptible to developing cognitive distortions. These are therefore not related to a lack of knowledge or information regarding the game (Lambos and Delfabbro 2007). According to Sévigny and Ladouceur (2003), pathological gamblers will experience two cognitive states: one focused on taking into account rational and objective probabilities, and another primarily focused on the activity and the expected results. Thus, even individuals with a good knowledge of probabilities and principles could present cognitive distortions that would be activated in gambling situations (Barrault and Varescon 2013). These irrational beliefs coexist with and oppose the rational beliefs of the gamblers. This cognitive change can be explained by the concept of heuristic control. In fact, in a particular class of situations, such as gambling, individuals are more likely to overestimate the amount of their perceived control over results; particularly when they are 
strongly committed to the task and/or they have a strong desire for results (Clark 2014; Delfabbro et al. 2006).

The presence of such cognitive distortions in gamblers is widely documented in the literature (Clark 2014). Hence, a model representing the five major beliefs related to gambling may be clinically significant (Raylu and Oei 2004). Gambling-related expectancies is more about the perception of the expected impact on the game itself than the hope of happiness, pleasure, or other types of emotions with personal utility that can be derived from the game. Illusion of control corresponds to the perceived controllability over the results of a game, while predictive control is the perception of predicting the outcome of the game. The belief about the inability to stop gambling refers to the perception of being unable to resist an urge to gamble. Finally, interpretative bias is characterized by an attributional belief, that is to say promoting the successful continuation of gambling and allocating losses to external factors.

Furthermore, cognitive distortions increase with the severity of gambling: problem gamblers seem to have more than non-problem gamblers (Miller and Currie 2008). They tend to overestimate the role of skill in games and consider gambling a financially profitable activity. However, the desire to win money causes losses that can be fueled by cognitive distortions. Delfabbro et al. (2006) implicitly suggested that gambling motives could influence cognitive distortions, particularly the illusion of control.

Although motivations vary according to the type of population studied (age and gender) (Dowling 2013; Sundqvist et al. 2016), the type of game, although this is not studied here (Binde 2013; Lee et al. 2007), and the severity of gambling (Francis et al. 2014), some of them are found fairly consistently in the literature. The motivational factor most often raised is financial gain, but others have also been highlighted: for fun or amusement, against boredom (Lam 2007; Neighbors et al. 2002), to escape from routine (Loroz 2004), to socialize, for excitement (Lee et al. 2007), for the challenge (Chantal et al. 1994), to escape from stress (Lee et al. 2007) or to escape depressive affects (Stewart and Zack 2008). These motives seem to reflect the expectations of gamblers about, on the one hand, the positive aspects of the reward of gambling behavior and, on the other hand, its potential to reduce negative affects.

Several models have been proposed to explain what motivates and animates gamblers; those of Binde (2013) and Milosevic and Ledgerwood (2010), who identified enhancement, coping and social motivation. Enhancement motivation refers to the presence of sensationseeking, impulsiveness, a sense of excitement felt for the game and coping. Gamblers wishing to regulate their emotional states would have a high level of this motivation whereas gamblers with a high level of coping would be characterized by a set of inappropriately used behaviors to escape their negative emotional state (Bonnaire et al. 2009; Vachon and Bagby 2009). Lastly, gamblers with a high level of social motivation play to establish a social affiliation (for fun with friends, for example) and would not present psychopathological disorders. Added to this is the financial motivation, already mentioned, which cannot be dissociated from this type of gambling (Dechant 2013).

To date, much empirical research has been carried out on cognitive distortions. However, no study has focused specifically on the link between these variables and gambling motives. Thus, our objectives were to assess gambling practice, gambling motives and cognitive distortions in terms of their presence and nature in gamblers, to compare them between the different types of gamblers, to determine the link between motivations and cognitions, and also to explain the nature of the relationship between gambling motivations and cognitive distortions. In view of these objectives, it was hypothesized that (1) problem gamblers would show a higher level of gambling motives and a higher level of cognitive 
distortions than non-problem gamblers; (2) there would be strong correlations between these two variables and with gambling severity; and (3) gambling motives would be a strong predictor of cognitive distortions.

\section{Methods}

\section{Participants}

Gambler participants were recruited between June 2016 and October 2016 through online gambling forums (Bet Clever, Club Poker). After receiving an authorization from the administrators, an announcement was posted on the "presentation" tab of the gambler community. Members interested in participating in the study had to click on the LimeSurvey ${ }^{\circledR}$ link provided in order to access the study (information, consent forms and questionnaires). All participants were at least 18 years of age, fluent French speakers, and with a regular online or live gambling activity (at least once a week). This criterion of regularity has been used previously in the literature (Bonnaire et al. 2009; Barrault and Varescon 2012). Finally, 259 male poker gamblers responded to all the questionnaires including $24 \%$ of non-problem gamblers (assessed by the South Oaks Gambling ScreenSOGS score under 3), 61.7\% of at risk-problem gamblers (SOGS score between 3 and 4) and $14.3 \%$ of problem gamblers (SOGS score equal to or higher than 5).

The Ethics Committee approved the study (IRB number: 20162200001072) and informed consent was obtained from all participants, who took part freely and voluntarily.

\section{Materials}

\section{Sociodemographic and Gaming Data}

Age, gender, marital status, level of education, household composition, professional activity and social-professional category were assessed. Gaming data were obtained using a questionnaire especially designed for this study, including all types of gambling (live and online).

\section{South Oaks Gambling Screen (SOGS)}

The SOGS (Lesieur and Blume 1987) was validated in French by Lejoyeux (1999). This is a self-administered 20-item questionnaire that assesses lifetime and current (occurring in the last 12 months) gambling habits and problems. A score less than or equal to 2 corresponds to the absence of problem gambling, a score of 3 or 4 corresponds to risky or problematic gambling, while a score greater than or equal to 5 defines the individual as a probable pathological gambler. In our study, this questionnaire appears only relevant for the current period (in the last 12 months) so we chose to remove the lifetime assessment. The SOGS shows satisfactory reliability and validity in the general population and in problem gamblers (Stinchfield 2002). In the current sample, Cronbach's alpha was .72, indicating good internal consistency. 


\section{Gambling Motives Questionnaire-Financial (GMQ-F)}

The Gambling Motives Questionnaire (GMQ - Stewart and Zack 2008) is a 15-item questionnaire directly adapted from the Drinking Motives Questionnaire (Cooper et al. 1992) assessing three types of gambling motive: "enhancement"-to increase positive emotions (5 items), "coping" - to reduce or avoid negative emotions (5 items), and "social" - to increase social affiliation (5 items). Dechant (2013) then proposed adding 9 items to assess the financial motivation of gamblers, a non-negligible factor. The resulting GMQF tool was translated and validated in French (Devos et al. 2017). Items were rated on a 4-point Likert scale ranging from 1 (never or almost never) to 4 (almost always or always). This questionnaire has shown favorable psychometric properties on middle-aged adult gamblers (Dechant and Ellery 2011). In the present study, Cronbach's alpha for the total scale $(\alpha=.80)$ and for each subscale was satisfactory: enhancement $(\alpha=.80)$, coping $(\alpha=.76)$, social $(\alpha=.65)$ and financial $(\alpha=.67)$.

\section{Gambling Related Cognition Scale (GRCS)}

The GRCS (Raylu and Oei 2004), validated in French (Grall-Bronnec et al. 2012), is a 23 -item self-report that records common thoughts associated with problem gambling. This questionnaire uses a seven-point Likert scale ranging from 1 (strongly disagree) to 7 (strongly agree) that provides a total score (23-161). Items are grouped into five subscales: predictive control (6 items), illusion of control (4 items), interpretative bias (4 items), gambling expectancies ( 4 items), and inability to stop (5 items). The higher the score is, the greater the gambling-related cognitions are. In our study, the internal consistency for the total score $(\alpha=.84)$ and for each subscore was adequate: gambling expectancies $(\alpha=.62)$, illusion of control $(\alpha=.75)$, predictive control $(\alpha=.54)$, perceived inability to stop $(\alpha=.84)$, and interpretative bias $(\alpha=.57)$.

\section{Data Analyses}

All data were analyzed using SPSS $^{\circledR}$, version 21, and were tested with a two-sided significance level of .05. Descriptive statistics for quantitative measures (mean, standard deviation) and for qualitative measures (percentage) were first calculated. To estimate the group effect regarding sociodemographic dimensions, and regarding the results of questionnaires, Chi squared tests were used for categorical measures and ANOVA for continuous ones (non-problem gamblers-NPGs vs. at risk-problem gamblers-RPGs vs. probable pathological gamblers-PPGs). Next, Spearman correlations were made between SOGS scores and the scores and subscores of the GMQ and GRCS. Then, one model of linear regression analysis was designed with the gambling motives and the problem gambling as the independent variables. Separate models were calculated for each scale (SOGS and GMQ) and subscale score. Finally, a multivariate linear regression analysis was designed with all the predictors with a significant effect revealed in the previous independent models. 


\section{Results}

\section{Sociodemographic Characteristics and Gambling}

Two hundred and fifty-nine (259) male poker gamblers completed the online questionnaires. Sociodemographic data, SOGS scores and the characteristics of gambling practices are detailed in Table 1. For the entire sample, the average age was 33.9 years ( $\mathrm{SD}=9.3$ ). Statistical analyses (ANOVA and $\mathrm{Chi}^{2}$ ) showed significant differences between NPGs $(\mathrm{n}=62)$, RPGs $(\mathrm{n}=160)$ and PPGs $(\mathrm{n}=37)$ only for professional activity and socioprofessional category in terms of sociodemographic variables $(p<.05)$.

\section{Scale and Questionnaire Results}

The results from each scale and the comparison between groups (ANOVA) are presented in Table 2. Table 3 shows the correlations between scales and subscales.

\section{Gambling Motives Questionnaire-Financial (GMQ-F)}

The ANOVA results revealed that PPGs had significantly higher scores than the two other groups for the GMQ overall score $(p=.001)$ and all subscores $(p=.012$ for coping and $p=.001$ for the others) except for "social" ( $p=.088, p>.05)$.

\section{Gambling-Related Cognitions Scale (GRCS)}

The ANOVA showed that PPGs displayed significantly higher GRCS scores than the two other groups $(p=.001)$, for the general scale and for all subscales ( $p$ value ranging from .001 to .18$)$.

In general, gambling motives (except social motivation) and cognitive distortions increased with the severity of the gambling practice $(p<.05)$. Moreover, significant correlations between problem gambling, cognitive distortions and gambling motives were observed $(p<.05)$. Gambling motives (overall GMQ-F) appeared to be significantly and strongly correlated with a specific dimension of cognitive distortions (i.e. gambling-related expectancies $)(\mathrm{r}=.51, p<.05)$.

\section{Multiple Linear Regression}

A three-step regression was conducted. First, a simple linear regression model was carried out to determine whether the components of gambling motives (independent variable) could predict problem gambling (SOGS score). It showed that overall motivations explained $22.0 \%$ of probable pathological gambling in our sample (Adjusted $\mathrm{R}^{2}=.217$; $\mathrm{t}=8.521 ; p=.001)$. In gambling motives, coping appeared to be the main significant predictor $\left(17.7 \% ; \mathrm{R}^{2}=.174 ; \mathrm{t}=7.444 ; p=.001\right)$ of probable pathological gambling, followed closely by financial motivation $\left(17.2 \% ; \mathrm{R}^{2}=.169 ; \mathrm{t}=7.304 ; p=.001\right)$. The second step included, one by one, sociodemographic variables, gambling motives (scale and subscales) and the SOGS score as predictors of cognitive distortions. The results showed that no sociodemographic variables significantly predicted cognitive distortions $(p>.05)$. However, on their own, gambling motives (overall GMQ-F) explained $34.8 \%$ of cognitive distortions present in our sample (Adjusted $\mathrm{R}^{2}=.345 ; \mathrm{t}=11.712 ; p=.001$ ), 
Table 1 Sociodemographic data and gambling practices

\begin{tabular}{|c|c|c|c|c|c|c|}
\hline & $\begin{array}{l}\text { NPG } \\
(\mathrm{n}=62) \\
\text { Mean }(\mathrm{SD})\end{array}$ & $\begin{array}{l}\text { RPG } \\
(\mathrm{n}=160) \\
\text { Mean }(\mathrm{SD})\end{array}$ & $\begin{array}{l}\text { PPG } \\
(\mathrm{n}=37) \\
\text { Mean (SD) }\end{array}$ & $\begin{array}{l}\text { Total } \\
(\mathrm{n}=259) \\
\text { Mean }(\mathrm{SD})\end{array}$ & $\begin{array}{l}\text { ANOVA } \\
\text { F }\end{array}$ & $p$ \\
\hline Age & $37.7(10.3)$ & $32.5(8.9)$ & $33.8(8.1)$ & $33.9(9.3)$ & 7.329 & $.001 *$ \\
\hline \multirow[t]{2}{*}{ SOGS } & $.0(.0)$ & $2.0(1.1)$ & $7.1(2.8)$ & $2.2(2.5)$ & 319.957 & $.000 * *$ \\
\hline & $\mathrm{N}(\%)$ & $\mathrm{N}(\%)$ & $\mathrm{N}(\%)$ & $\mathrm{N}(\%)$ & $\chi^{2}$ & $p$ \\
\hline Education & & & & & 14.316 & .074 \\
\hline No graduate certificate & $0(.0)$ & $1(.6)$ & $0(.0)$ & $1(.4)$ & & \\
\hline$<$ High school degree & $8(12.3)$ & $7(4.3)$ & $5(12.8)$ & $20(7.5)$ & & \\
\hline High school degree & $12(18.5)$ & $28(17.8)$ & $8(25.6)$ & $48(19.1)$ & & \\
\hline Graduate study degree & $39(64.6)$ & $123(76.7)$ & $24(61.5)$ & $186(71.5)$ & & \\
\hline Others & $3(4.6)$ & $1(.6)$ & $0(.0)$ & $4(1.5)$ & & \\
\hline Family situation & & & & & 8.575 & .199 \\
\hline Single & $25(41.5)$ & 79 (49.7) & $15(43.6)$ & $119(46.8)$ & & \\
\hline Married or in a couple & $33(52.3)$ & $73(45.4)$ & $20(51.3)$ & $126(47.9)$ & & \\
\hline Divorced & $2(3.1)$ & $8(4.9)$ & $2(5.1)$ & $12(4.5)$ & & \\
\hline Widowed & $2(3.1)$ & $0(.0)$ & $0(.0)$ & $2(.7)$ & & \\
\hline Professional activity & & & & & 28.313 & $.013^{*}$ \\
\hline Full-time & $37(60.0)$ & $83(51.5)$ & $26(66.7)$ & $146(55.8)$ & & \\
\hline Part-time & $1(1.5)$ & $8(4.9)$ & $0(.0)$ & $9(3.4)$ & & \\
\hline Irregular & $6(9.2)$ & $13(8.0)$ & $1(5.1)$ & $20(7.9)$ & & \\
\hline Unemployed & $8(12.3)$ & $11(6.7)$ & $6(15.4)$ & $25(9.4)$ & & \\
\hline Student & $3(6.2)$ & $26(16.6)$ & $3(10.3)$ & $32(13.1)$ & & \\
\hline $\begin{array}{l}\text { Disability/long-term sick } \\
\text { leave }\end{array}$ & $0(.0)$ & $2(1.8)$ & $0(.0)$ & $2(1.1)$ & & \\
\hline Retired & $4(6.2)$ & $1(.6)$ & $0(.0)$ & $5(1.9)$ & & \\
\hline Other & $3(4.6)$ & $16(9.8)$ & $1(2.6)$ & $20(7.5)$ & & \\
\hline $\begin{array}{l}\text { Socio-professional } \\
\text { category }\end{array}$ & & & & & 25.451 & $.030^{*}$ \\
\hline Agricultural worker & $0(.0)$ & $1(.6)$ & $0(.0)$ & $1(.4)$ & & \\
\hline Craftsman & $4(7.7)$ & $13(8.6)$ & $1(2.6)$ & $18(7.5)$ & & \\
\hline Executive & $23(38.5)$ & $67(41.1)$ & $12(30.8)$ & $102(39.0)$ & & \\
\hline Intermediate prof. & $7(10.8)$ & $10(6.7)$ & $4(12.8)$ & $21(8.6)$ & & \\
\hline Employee & $16(24.6)$ & $20(12.3)$ & 7 (17.9) & $43(16.1)$ & & \\
\hline Workman & $4(6.2)$ & $8(4.9)$ & $7(17.9)$ & $19(7.1)$ & & \\
\hline Retired & $1(1.5)$ & $0(.0)$ & $0(.0)$ & $1(.4)$ & & \\
\hline Others without prof. & $7(10.8)$ & $41(25.8)$ & $6(17.9)$ & $54(21.0)$ & & \\
\hline Gamblers with children & $26(41.5)$ & $50(31.3)$ & & $15(34.8)$ & 2.792 & .248 \\
\hline
\end{tabular}

$N P G$ Non-problem gamblers, $R P G$ Risk-problem gamblers, $P P G$ problem gamblers, Others without prof. includes students. ** $p<.001 ; * p<.05$

whereas problem gambling (overall SOGS) explained $22.4 \%$ of these cognitive distortions (Adjusted $\mathrm{R}^{2}=.221 ; \mathrm{t}=8.609 ; p=.001$ ). Although this model was statistically significant, two dimensions of gambling motives, coping and financial, constituted significant 
Table 2 SOGS, GMQ and GRCS scores and subscores

\begin{tabular}{|c|c|c|c|c|c|c|}
\hline & $\begin{array}{l}\text { NPG } \\
(n=65)\end{array}$ & $\begin{array}{l}\text { RPG } \\
(\mathrm{n}=163)\end{array}$ & $\begin{array}{l}\text { PPG } \\
(n=39)\end{array}$ & $\begin{array}{l}\text { Total } \\
(\mathrm{N}=267)\end{array}$ & $\mathrm{F}$ & $p$ \\
\hline SOGS mean (SD) & $.0(.0)$ & $2.0(1.1)$ & $7.1(2.8)$ & $2.2(2.5)$ & 319.957 & $.000 * *$ \\
\hline GMQ mean (SD) & $40.8(7.0)$ & $45.7(7.9)$ & $52.8(11.0)$ & $45.5(8.9)$ & 24.8 & $.000 * *$ \\
\hline Enhancement & $12.7(3.4)$ & $13.8(3.5)$ & $14.8(3.6)$ & $13.7(3.5)$ & 4.5 & $.012 *$ \\
\hline Coping & $7.6(2.1)$ & $8.3(2.8)$ & $11.3(3.5)$ & $8.6(3.0)$ & 21.9 & $.000 * *$ \\
\hline Social & $5.5(2.0)$ & $5.6(1.7)$ & $6.3(2.3)$ & $5.7(1.9)$ & 2.4 & .088 \\
\hline Financial & $15.1(4.0)$ & $18.0(4.0)$ & $20.5(5.9)$ & $17.6(4.6)$ & 19.1 & $.000 * *$ \\
\hline GRCS mean (SD) & $54.2(12.6)$ & $64.1(14.7)$ & $79.3(23.6)$ & $63.9(17.5)$ & 29.0 & $.000 * *$ \\
\hline $\begin{array}{l}\text { Gambling-related } \\
\text { expectancies }\end{array}$ & $12.4(3.7)$ & $14.2(4.4)$ & $16.6(5.5)$ & $14.1(4.6)$ & 10.7 & $.000 * *$ \\
\hline Illusion of control & $5.1(1.9)$ & $5.2(2.6)$ & $7.9(5.7)$ & $5.6(3.2)$ & 12.0 & $.000 * *$ \\
\hline Predictive control & $14.3(4.8)$ & $16.0(5.1)$ & $17.4(6.7)$ & $15.8(5.4)$ & 4.1 & $.018^{*}$ \\
\hline $\begin{array}{l}\text { Inability to stop } \\
\text { gambling }\end{array}$ & $8.7(3.9)$ & $12.5(6.0)$ & $20.9(7.3)$ & $12.8(6.8)$ & 52.8 & $.000 * *$ \\
\hline Interpretative bias & $13.7(4.5)$ & $16.1(4.9)$ & $16.6(5.1)$ & $15.6(4.9)$ & 6.3 & $.002 *$ \\
\hline
\end{tabular}

$N P G$ non-problem gamblers, $R P G$ risk of problem gamblers, $P P G$ problem gamblers, SOGS South Oaks Gambling Screen, GMQ Gambling Motives Questionnaire, GRCS Gambling-Related Cognitions Scale. ** $p<.001 ; * p<.05$

Table 3 Correlations between GMQ and GRCS total and subscales

\begin{tabular}{|c|c|c|c|c|c|c|c|}
\hline & SOGS & GRCS & GRCS1 & GRCS2 & GRCS3 & GRCS4 & GRCS5 \\
\hline SOGS & 1 & $.39 * *$ & $.23 * *$ & $.15^{*}$ & $.13 *$ & $.49 * *$ & $.16^{*}$ \\
\hline GMQ & $.39 * *$ & $.56^{* *}$ & $.51 * *$ & $.24 * *$ & $.31 * *$ & $.46^{* *}$ & $.25 * *$ \\
\hline GMQ enhancement & $.21 * *$ & $.37 * *$ & $.39 * *$ & .07 & $.19 * *$ & $.31 * *$ & $.14^{*}$ \\
\hline GMQ coping & $.32 * *$ & $.42 * *$ & $.44 * *$ & $.19^{* *}$ & $.17 * *$ & $.40 * *$ & $.14 *$ \\
\hline GMQ social & .10 & $.29 * *$ & $.24 * *$ & $.22 * *$ & $.15^{*}$ & $.25 * *$ & .11 \\
\hline GMQ financial & $.34 * *$ & $.40 * *$ & $.32 * *$ & $.20 * *$ & $.29 * *$ & $.28 * *$ & $.26 * *$ \\
\hline
\end{tabular}

SOGS South Oaks Gambling Screen, GRCS Gambling-Related Cognitions Scale, GRCS1 Gambling-related expectancies, GRCS2 Illusion of control, GRCS3 Predictive control, GRCS4 Inability to stop gambling, GRCS5 Interpretative bias, GMQ Gambling Motives Questionnaire. ** $p<.001 ; * p<.05$

predictors (22.3 and 21.4\%, respectively) of cognitive distortions (Adjusted $\mathrm{R}^{2}=.220$; $\mathrm{t}=8.588$ for coping, and Adjusted $\mathrm{R}^{2}=.211 ; \mathrm{t}=8.373$ for financial; $p=.001$ for both).

Finally, a multivariate analysis was conducted (see Table 4). All the significant predictors listed below were entered simultaneously with cognitive distortions as the dependent variable. This multivariate model accounted for $39.7 \%$ of the variance of cognitive distortions (Adjusted $\mathrm{R}^{2}=.393 ; p<.05$ ). However, only three significant predictors were highlighted: overall gambling motives and problem gambling were positively related to cognitive distortions (respectively, $\mathrm{t}=8.586$ and $\mathrm{t}=4.580 ; p=.001$ ), while "enhancement" motivation was related negatively to cognitive distortions $(\mathrm{t}=-2.400 ; p<.05)$. 
Table 4 Multivariate analyses

\begin{tabular}{|c|c|c|c|c|c|}
\hline GRCS (dependent variable) & $R^{2}$ & Adjusted $R^{2}$ & Bêta & $\mathrm{t}$ & $p$ \\
\hline \multicolumn{6}{|c|}{ Model with subscores (predictors) } \\
\hline GMQ & .397 & .393 & .472 & 8.586 & $.000^{*}$ \\
\hline Enhancement & & & -.179 & -2.400 & $.017 *$ \\
\hline Coping & & & .073 & .970 & .333 \\
\hline Social & & & -.073 & -1.499 & .135 \\
\hline Financial & & & .121 & 1.784 & .076 \\
\hline SOGS & & & .252 & 4.580 & $.000 *$ \\
\hline
\end{tabular}

SOGS South Oaks Gambling Screen, GRCS Gambling-Related Cognitions Scale, GMQ Gambling Motives Questionnaire. $* p<.05$

\section{Discussion}

This research is the first to assess gambling motives and cognitive distortions jointly in poke players. One of the purposes of this study was to investigate whether gambling motives explain cognitive distortions.

The main results show that gambling motives are a strong predictor of cognitive distortions. This close linkage enables us to hypothesize that gamblers with more motives to gamble (both in quality and in quantity) are more likely to develop and maintain cognitive distortions during gambling, such as the failure to appreciate the independence of turns (GRCS predictive control) and expectancies that gambling will be exciting and/or relieve negative affect (GRCS gambling related-expectancies) for example. Cognitive distortions are mainly explained by financial and coping motivation. Greed and the tendency to escape from daily difficulties may explain the presence of more or fewer cognitive distortions. Indeed, the desire to succeed and win money may be overestimated by gamblers while creating financial losses. Moreover, winning money probably enables some gamblers to escape their routine and their difficulties, which may reinforce cognitive distortions. In addition, the game's outcome modulates the gambler's mood: more depressive affects are observed after a loss, and more euphoria after a win.

The link between gambling motives and gambling severity has already been studied in the literature (Francis et al. 2014). Our results confirm these results and show that gambling motives are significantly correlated to the degree of gambling severity. Moreover, the differences between the three groups of gamblers (NPGs, RPGs and PPGs) are statistically significant for all dimensions of the GMQ-F scale, except for "social" motivation. Earlier research showed that PPGs gamble more to escape problems compared to recreational gamblers (Burlacu et al. 2013; Clarke 2008; Platz and Millar 2001), which is supported in this study. Respondents with a gambling problem have significantly higher scores than RPGs and NPGs: first, on coping, secondly, on financial motivation and then on enhancement. The content of the coping subscale might mediate the negative affects found in pathological gamblers (Connor-Smith and Flachsbart 2007). Furthermore, our study highlights the nature of the relationship between these two variables: gambling motives explain $22.0 \%$ of problem gambling. Individual differences, particularly in terms of motives, may be a vulnerability factor of problem gambling behavior. 
Multivariate analyses reveal that gambling severity associated with gambling motives accounts for $39.7 \%$ of cognitive distortions, with the enhancement motive negatively related to cognitive distortions. We can hypothesize that the acquisition of a set of knowledge and know-how, in order to progress, opposes the potential installation of cognitive distortions. For example, gamblers motivated by improvement are well informed about the game (probabilities, gambling techniques, etc.). Nevertheless, our sample is mainly composed of male gamblers, who are more oriented towards, on the one hand, games of skill (poker and sports betting), and on the other hand, enhancement (Gandolfo and Debonis 2014). The enhancement motives may reflect a desire to increase self-esteem. However, changes in self-perception are directly linked to major trends in success and failure, also related to the acquired skills.

Nevertheless, the literature also reports the link between the severity of gambling and cognitive distortions, putting forward cognitive distortions as a risk factor and not the other way round (Barrault and Varescon 2013; Cunningham et al. 2014; Navas et al. 2016; Romo et al. 2016). In our study, all GRCS measures were higher in the PG group than in the other two groups (NPGs and RPGs). The inability to stop gambling appears as the main reported cognitive distortion. However, this cognitive distortion component is one of the criteria characterizing pathological gambling. This result highlights a certain awareness in problem gamblers of their difficulties in controlling their gambling behavior. Unlike the results found previously, in pathological gamblers (Michalczuk et al. 2011; Navas et al. 2016) and pathological gambling poker players (Barrault and Varescon 2013), the illusion of control does not appear to be an important belief. However, it is possible that gamblers subjectively experience the illusion of control, without it concretely impacting their way of gambling. Gamblers could also have underestimated their answers as they were not in gambling conditions when filling out the questionnaires. This is consistent with the results found by Dannewitz and Weatherly (2007). Moreover, several factors may influence cognitive distortions, including the degree of involvement of the gambler and some features of the game (Ladouceur and Sévigny 2005). The literature highlights, on one hand, a quantitative difference in cognitive distortions depending on game frequency and intensity (the level of irrational beliefs increases with the intensity of gambling practice) and on the other hand, a qualitative difference (the role of skill in games and the perception of the game as financially profitable are more present in pathological gamblers) (Delfabbro et al. 2006; Källmen et al. 2008; Miller and Currie 2008; Moodie 2008; Raylu and Oei 2004). Different groupings of preferred gambling type, such as games of skill and games of luck, could be another way to examine cognitive distortions.

To our knowledge, few studies have focused on gambling motives. This is why our study aimed to provide some additional information by identifying and comparing gambling motivations based on gambling practices. However, there are several limitations to the interpretation and generalization of the results. First, participants are only male poker gamblers, who are not representative of the gambler population due to their specific profile. In order to limit this bias, studies need to be carried out on groups of gamblers created according to the type of game practiced. Moreover, we cannot generalize the results to women gamblers while a gender effect has been demonstrated in some previous studies. In fact, in both pathological and non-pathological gamblers, women appear to have less intense cognitive distortions than men (Dannewitz and Weatherly 2007; Moodie 2008; Raylu and Oei 2004). Nevertheless, we tried to constitute a sample as representative as possible by recruiting our participants in ecological settings (Internet forums). Secondly, we used the SOGS (Lesieur and Blume 1987) to screen for gambling problems: in our sample, we observed $14.3 \%$ of probable pathological gamblers, which is similar to the 
results found by Barrault and Varescon (2013) using the SOGS, and by Wood et al. (2007) using the DMS-IV-TR criteria (APA 2003). Although the SOGS is known to foster false positives in a general population (Stinchfield 2002), it is still the most used screening tool in research. Another limitation of this study is the cross-sectional design. Indeed, it seems to make changes in motivations and/or in involvement over time and in terms of gambling practice. A longitudinal or qualitative study would allow access to these evolutionary elements. Moreover, for practical reasons, our results are based on the prevalence during the current period (the last year). Finally, we were unable to compare online and live gamblers because the majority of our participants reported having both types of practices. Another approach could be to compare, as far as possible in terms of feasibility, exclusive online gamblers and live gamblers. Despite these limitations, the present study offers interesting results and research perspectives. The relationship between gambling problems in all gamblers, gambling motives and cognitive distortions merits further study.

\section{Conclusions and Implications}

In conclusion, gambling motives differ between gamblers depending on the intensity and severity of the gambling practice. The level of risky gambling is associated with motivations and should be considered during tests or assessment. Moreover, the presence of cognitive distortions is impacted by the presence of gambling motives. A longitudinal study would show the evolution of motivations and cognitive distortions (in terms of numbers and importance) in gamblers engaging in regular gambling activity.

The differences in psychological functioning between non-problem gamblers, at riskgamblers and those with a probable problem demonstrate the need for further research to understand better the factors involved in gambler behavior, with the objective of prevention and care for gamblers. With these results, we can hypothesize that a systematic assessment of gambling motives of gamblers would enable us to target the type of intervention required. Moreover, due to the possible presence of varying levels of cognitive distortions, a motivational and cognitive intervention (such as cognitive remediation) would act on the two components of gambling, directly linked to gambling problems.

Acknowledgements Sincere gratitude is expressed to all the gambler participants who took the time to complete the questionnaires. We also thank the Bet Clever and Club Poker websites, which agreed to publish our recruitment announcement.

Funding This study was funded by GIS Jeu et Société (FDJ) (Grant number CF UNI 001 3105). The funding organization had no role in the design or conduct of the study; data collection, analysis, and interpretation; preparation, review and approval of the manuscript.

\section{Compliance with Ethical Standards}

Conflict of interest Paul Brunault reports personal fees (honoraria for speaking at symposia) and nonfinancial support (travel for participating in continuing medical education sessions) from Lundbeck, personal fees (honoraria for speaking at symposia) from Astra-Zeneca, and personal fees (co-investigator of a clinical trial) from DNA Pharma, outside the submitted work. Sasha Mathieu, Servane Barrault and Isabelle Varescon declare that they have no conflict of interest.

Human and Animal Rights This article does not contain any studies with animals performed by any of the authors. All procedures performed in studies involving human participants were in accordance with the ethical standards of the institutional and/or national research committee and with the 1964 Helsinki declaration and its later amendments or comparable ethical standards. 
Ethical Approval Ethical approval for this study was obtained from the CERES Committee (IRB number: 20162200001072). All participants chose to participate by clicking on the study invitation link and provided their informed consent to participate prior to beginning the study.

Open Access This article is distributed under the terms of the Creative Commons Attribution 4.0 International License (http://creativecommons.org/licenses/by/4.0/), which permits unrestricted use, distribution, and reproduction in any medium, provided you give appropriate credit to the original author(s) and the source, provide a link to the Creative Commons license, and indicate if changes were made.

\section{References}

American Psychiatric Association (APA). (2003). DSM-IV-TR: Manuel diagnostic et statistique des troubles mentaux (4th ed. rev. J. -D. Guelfi \& M. -A. Crocq, trans.). Paris, France: Masson.

Barrault, S., \& Varescon, I. (2012). Distorsions cognitives et pratiques de jeux de hasard et d'argent: état de la question. Psychologie Française, 57(1), 17-29.

Barrault, S., \& Varescon, I. (2013). Cognitive distortions, anxiety, and depression among regular and pathological gambling online poker players. Cyberpsychology, Behavioral, and Social Network, 16(3), $183-188$.

Barrault, S., Untas, A., \& Varescon, I. (2014). Special features of poker. International Gambling Studies, 14(3), 492-504.

Binde, P. (2013). Why people gamble: a model with five motivational dimensions. International Gambling Studies, 13(1), 81-97.

Bjerg, O. (2010). Problem gambling in poker: money, rationality and control in a skill-based social game. International Gambling Studies, 10(3), 239-254.

Bonnaire, C., Bungener, C., \& Varescon, I. (2009). Subtypes of French pathological gamblers: Comparison of sensation seeking, alexithymia, and depression scores. Journal of Gambling Studies, 25, 455-471.

Burlacu, S., Romo, L., Lucas, C., \& Legauffre, C. (2013). La motivation pour les jeux de hasard et d'argent dans un groupe de joueurs français. Annales Médico-Psychologiques, 171, 410-414.

Chantal, Y., Vallerand, R. J., \& Vallieres, E. F. (1994). Construction et validation de l'échelle de motivation relative aux jeux de hasard et d'argent. On the development and validation of the Gambling Motivation Scale (GMS). Society and Leisure, 17, 189-212.

Clark, L. (2014). Disordered gambling: The evolving concept of behavioral addiction. Annals of the New York Academy of Sciences, 1327(1), 46-61.

Clarke, D. (2008). Older adults' gambling motivation and problem gambling: A comparative study. Journal of Gambling Studies, 24, 175-192.

Connor-Smith, J. K., \& Flachsbart, C. (2007). Relations between personality and coping: A meta-analysis. Journal of Personality and Social Psychology, 93, 1080-1107.

Cooper, M. L., Russell, M., Skinner, J. B., \& Windle, M. (1992). Development and validation of a threedimensional measure of drinking motives. Psychological Assessment, 4, 123-132.

Costes, J. M., Pousset, M., Eroukmanoff, V., Le Nézet, O., Richard, J. B., Guignard, R., et al. (2011). Les niveaux et pratiques des jeux de hasard et d'argent en 2010. Tendances, 77, 1-8.

Cunningham, J. A., Hodgins, D. C., \& Toneatto, T. (2014). Relating severity of gambling to cognitive distortions in a representative sample of problem gamblers. Journal of Gambling Issues, 29(29), 1-6.

Dannewitz, H., \& Weatherly, J. (2007). Investigating the illusion of control in mildly depressed and nondepressed individuals during video-poker play. Journal of Psychology, 141(3), 307-319.

Dechant, K. (2013). Show me the money: Incorporating financial motives into the gambling motives questionnaires. Journal of Gambling Behavior, 30(4), 949.

Dechant, K., \& Ellery, M. (2011). The effect of including a monetary motive item on the gambling motives questionnaire in a sample of moderate gamblers. Journal of Gambling Studies, 27(2), 331-344.

Delfabbro, P., Lahn, J., \& Grabosky, P. (2006). It's not what you know but how you use it: Statistical knowledge and adolescent problem gambling. Journal of Gambling Studies, 22, 179-193.

Devos, G., Challet-Bouju, G., Burnay, J., Maurage, P., Grall-Bronnec, M., \& Billieux, J. (2017). Adaptation and validation of the Gambling Motives Questionnaire-Financial (GMQ-F) in a sample of Frenchspeaking gamblers. International Gambling Studies. doi:10.1080/14459795.2016.1264080.

Dowling, N. (2013). Treatment of female problem gambling. In D. Richard, A. Blaszczynski, \& L. Nower (Eds.), The Wiley-Blackwell handbook of disordered gambling (pp. 225-250). Chichester: John Wiley and Sons Ltd. 
Francis, K. L., Dowling, N. A., Jackson, A. C., Christensen, D. R., \& Wardle, H. (2014). Gambling motives: Application of the reasons for gambling questionnaire in an Australian population survey. Journal of Gambling Studies, 31(3), 807-823.

Gandolfo, A., \& Debonis, V. (2014). Motivations for gambling and the choice between skill and luck gambling products: An exploratory study. Collana del Dipartimento di Scienze Economiche, 185, $1-35$.

Grall-Bronnec, M., Bouju, G., Sébille-Rivain, V., Gorwood, P., Boutin, C., Vénisse, J. L., et al. (2012). A French adaptation of the Gambling-Related Cognitions Scale (GRCS): A useful tool for assessment of irrational thoughts among gamblers. Journal of Gambling Issues, 27, 1-21.

Källmen, H., Andersson, P., \& Andren, A. (2008). Are irrational beliefs and depression mood more common among problem gamblers than non-gamblers? A survey study of Swedish problem gamblers and controls. Journal of Gambling Studies, 24, 441-450.

Ladouceur, R., \& Sevigny, S. (2005). Structural characteristics of video lotteries: effects of a stopping device on illusion of control and gambling persistence. Journal of Gambling Studies, 21(2), 117-132.

Lam, D. (2007). An exploratory study of gambling motivations and their impact on the purchase frequencies of various gambling products. Psychology and Marketing, 24, 815-827.

Lambos, C., \& Delfabbro, P. (2007). Numerical reasoning ability and irrational beliefs in problem gambling. International Gambling Studies, 7(2), 157-171.

Lee, H. P., Chae, P. K., Lee, H. S., \& Kim, Y. K. (2007). The five factor gambling motivation model. Psychiatry Research, 150, 21-32.

Lejoyeux, M. (1999). Echelles de dépistage du jeu pathologique. Neuropsychologie, 14, 67-71.

Lesieur, H. R., \& Blume, S. B. (1987). The South Oaks Gambling Screen (SOGS): A new instrument for the identification of pathological gamblers. American Journal of Psychiatry, 144, 1184-1188.

Loroz, P. S. (2004). Golden-age gambling: Psychological benefits and self-concept dynamics in aging consumers' consumption experiences. Psychology and Marketing, 21(5), 323-349.

Michalczuk, R., Bowden-Jones, H., Vederjo-Garcia, A., \& Clark, L. (2011). Impulsivity and cognitive distortions in pathological gamblers attending the UK National Problem Gambling Clinic: A preliminary report. Psychological Medicine, 41, 2625-2635.

Miller, N., \& Currie, S. (2008). A Canadian population level analysis of the role of irrational gambling cognitions and risky gambling practices as correlates on gambling intensity and pathological gambling. Journal of Gambling Studies, 24, 257-274.

Milosevic, A., \& Ledgerwood, D. M. (2010). The subtyping of pathological gambling: A comprehensive review. Clinical Psychology Review, 30(8), 988-998.

Moodie, C. (2008). Student gambling, erroneous cognition and awareness of treatment in Scotland. Journal of Gambling Issues, 21, 30-56.

Navas, J. F., Verdejo-Garcia, A., Lopez-Gomez, M., Maldonado, A., \& Perales, J. C. (2016). Gambling with rose-tinted glasses on: Use of emotion-regulation strategies correlates with dysfunctional cognitions in gambling disorder patients. Journal of Behavioral Addictions, 5(2), 271-281.

Neighbors, C., Lostutter, T. W., Cronce, M. J., \& Larimer, M. E. (2002). Exploring college student gambling motivation. Journal of Gambling Studies, 18, 361-370.

Platz, L., \& Millar, M. (2001). Gambling in the context of other recreation activity: A quantitative comparison of casual and pathological student gamblers. Journal of Leisure Research, 33(4), 383-395.

Raylu, N., \& Oei, T. (2004). The gambling related cognitions scale (GRCS): Development, confirmatory factor validation and psychometrics properties. Addiction, 99, 757-769.

Romo, L., Legauffre, C., Guilleux, A., Valleur, M., Magalon, D., Fatséas, M., et al. (2016). Cognitive distortions and ADHD in pathological gambling: A national longitudinal case control cohort study. Journal of Behavioral Addictions, 5(4), 649-657.

Sévigny, S., \& Ladouceur, R. (2003). Gambler's irrational thinking about chance events: The double switching concept. International Gambling Studies, 3(2), 163-172.

Stewart, S. H., \& Zack, M. (2008). Development and psychometric evaluation of a three dimensional Gambling Motives Questionnaire. Addiction, 103(7), 1110-1117.

Stinchfield, R. (2002). Reliability, validity and classification accuracy of the South Oaks Gambling Screen (SOGS). Addictive Behaviors, 27, 1-19.

Sundqvist, K., Jonsson, J., \& Wennberg, P. (2016). Gambling motives in a representative Swedish sample of risk gamblers. Journal of Gambling Studies, 32, 1231-1234.

Vachon, D. D., \& Bagby, R. M. (2009). Pathological gambling subtypes. Psychological Assessment, 21, $608-615$.

Wood, R., Griffiths, M., \& Parke, J. (2007). Acquisition, development and maintenance of online poker playing in a student sample. Cyberpsychology and Behavior, 10(3), 354-363. 